\section{Establishment of a Rapid Breeding System for Bletilla striata}

\section{Ze-yuan Mi}

National Engineering Laboratory for Resource Development of Endangered Chinese Crude Drugs in Northwest of China; Key Laboratory of the Ministry of Education for Medicinal Resources and Natural Pharmaceutical Chemistry; and College of Life Sciences, Shaanxi Normal University, Xi'an, Shaanxi, 710119, China

\section{Ding-hao Lv \\ Shanxi institute of Medicine and Life Sciences, Taiyuan, 030006, China}

Guang-hui Jiang, Jun-feng Niu, Shi-qiang Wang, and Zhe-zhi Wang National Engineering Laboratory for Resource Development of Endangered Chinese Crude Drugs in Northwest of China; Key Laboratory of the Ministry of Education for Medicinal Resources and Natural Pharmaceutical Chemistry; and College of Life Sciences, Shaanxi Normal University, Xi'an, Shaanxi, 710119, China

\section{Additional index words. Direct seeding, germination system, rapid propagation}

Abstract. Bletilla striata (Thunb. ex A. Murray) Rchb. f., a species of perennial herb of orchidaceae that has remarkable effects and high economic value, has been intensively studied by many scholars. Although this herb has many seeds, the germination rate is exceptionally low, which leads to decreased germplasm resources and increased market demand every year. To solve this problem, this study examined the aseptic germination system and the direct seeding technology system. On Murashige and Skoog (MS) medium, $2.0 \mathrm{mg} / \mathrm{L}$ 6-benzylaminopurine $(6-B A)$ and $1.0 \mathrm{mg} / \mathrm{L}$ naphthylacetic acid (NAA) were added before seed germination, and $70 \mathrm{~g} / \mathrm{L}$ banana juice and $0.5 \mathrm{mg} / \mathrm{L}$ NAA were added when rooting. Then, the seedlings were transplanted to a mixed substrate of humus, river sand, and bark (volume ratio of $3: 1: 1$ ). The direct seeding system consists of substrate treatment, sowing, seedling raising, seedling growth, and transplanting. Turfy soil, Huangjiang residue, and river sand were selected as the substrate. The results revealed that the germination rate was increased to $91.8 \%$, whereas the plantlet regeneration was increased to $82.0 \%$. After 180 days of cultivation, the plants could be transplanted as finished seedlings. The establishment of $B$. striata seedling system provides a safe, rapid, reliable production technology route for industrial development.

Bletilla striata, a perennial medicinal herb of the Orchidaceae family, is primarily distributed across the Hubei, Sichuan, Yunnan, Shaanxi, Guizhou, Jiangxi, and Jiangsu Provinces of China (Bai et al., 2018; Chen et al., 2019; Jiang et al., 2019). As a traditional Chinese medicine, it has been used for curing alimentary canal mucosal damage, ulcers, bruises, and burns for thousands of years (Xu et al., 2019; Zhang et al., 2019). Furthermore, it can be used to treat tuberculosis, malignant ulcers, hemorrhoids, anthrax, eye diseases, and silicosis in clinical practice, and it is widely used in the tobacco, chemical, and food industries (Chen et al., 2016; He et al., 2017a; Hirano et al., 2005).

There are many seeds in the fruits of $B$. striata, which are small, have no endosperm, and have a low germination rate under natural conditions (Guler, 2016; Wei et al., 2018). Because of the destruction and excessive development of natural habitats, wild $B$. striata resources have been severely damaged (Bai et al., 2018). Therefore, it has been listed as a rare and endangered wild
Spathoglottis plicata Blume (Haque and Ghosh, 2017).

We conducted relevant research of the characteristics of seeds and gradually solved the germination issue of $B$. striata seeds in a sterile environment, which makes it possible to produce several seedlings within a short time. Simultaneously, we attempted to breed the seeds of $B$. striata in the natural environment. For this study, an optimum tissue culture matrix and transplanting matrix were screened using an orthogonal experiment, and a new model of large-scale standardized breeding was explored through direct seeding.

\section{Materials and Methods}

Reagents and medicines. Analytically pure agar powder, NAA, sodium hydroxide, and 6-BA purine were purchased (Tianjin Tianli Chemical Reagent Co., Ltd.). Humus, river sand, crushed bark, vegetative soil, and perlite were purchased from the Xian Yanjin Road Flower Market.

Plant materials. Germplasm resources were planted at the National Engineering Laboratory for Resource Development of Endangered Crude Drugs in Northwest China. Pollination was completed via artificial pollination technology after flowering (from the end of April to May 2016). The fruits were collected at the mature stage, placed into the cowhide bag, and stored in a refrigerator for subsequent experiments.

Sterile germination. Seed viability was confirmed by 2,3,5-triphenyltetrazolium chloride (TTC) staining before sterile germination and field seeding (Briggs et al., 2009). The capsule was peeled carefully to extract the $B$. striata seeds, rinsed with sterile water, and disinfected with $75 \%$ alcohol and $0.1 \%$ corrosive sublimate.

Protocorm is an oblate globule formed during the in vitro culturing of plants that can form a complete plant through further germination and rooting. According to the preliminary experimental results, the main factors that influenced the germination of $B$. striata seeds were the type of medium, 6-BA purine, NAA, and the concentration of banana juice. Therefore, we adopted an orthogonal experimental method and selected three factors (Table 1) to optimize the seed germination medium.

Under aseptic conditions, the seeds were seeded in the preprepared medium for each experimental group and placed in a light incubator under a constant temperature and humidity. The temperature was maintained at $25 \pm 2{ }^{\circ} \mathrm{C}$ and the illumination intensity was 2000 to 3000 lx. The germination of $B$. striata seeds was observed using a stereomicroscope every $5 \mathrm{~d}$. After $30 \mathrm{~d}$, the final germination rate was calculated.

The growth of a plant is largely determined by the development of its roots. We used MS basic medium to investigate the effects of banana juice and NAA on root proliferation of $B$. striata tissue culture seedlings. Sterile seedlings $3.0 \mathrm{~cm}$ high were 
Table 1. L9 $\left(3^{3}\right)$ orthogonal experiment design table of B. striata seed germination.

\begin{tabular}{lccc}
\hline & \multicolumn{3}{c}{ Factors } \\
\cline { 2 - 4 } Group & Medium (A) & 6-BA (B) & NAA (C) \\
\hline 1 & MS & $0.0 \mathrm{mg} / \mathrm{L}$ & $0.0 \mathrm{mg} / \mathrm{L}$ \\
2 & $1 / 2 \mathrm{MS}$ & $1.0 \mathrm{mg} / \mathrm{L}$ & $0.5 \mathrm{mg} / \mathrm{L}$ \\
3 & Agar & $2.0 \mathrm{mg} / \mathrm{L}$ & $1.0 \mathrm{mg} / \mathrm{L}$ \\
\hline 6-BA = & 6-benzylaminopurine; $\mathrm{MS}=$ Murashige \\
and Skoog; NAA = naphthylacetic acid. $1 / 2 \mathrm{MS}$ \\
refers to half of the macroelements in MS.
\end{tabular}

transferred to different combinations of rooting media (Table 2). After $30 \mathrm{~d}$ of culturing, the changes in the seedling biomass in each experimental group were observed and counted.

According to the simulation of the original habitat combined with the unique growth habits, we created a variety of substrate formulas using the survival rate as the test standard to identify the optimal substrate for planting (Table 3 ). The survival rate and seedling growth of each experimental group were observed and recorded at $15 \mathrm{~d}$ and $30 \mathrm{~d}$ after transplantation.

Direct seeding of B. striata. The experiment was conducted at the Xi' an Hengfeng Biotechnology Co., Ltd. (lat. $34^{\circ} 08^{\prime} 03^{\prime \prime} \mathrm{N}$, long. 108 $37^{\prime} 32^{\prime \prime}$ E). We selected plastic sunlit greenhouses to conduct the field sowing experiments. Humus, river sand, and bark were initially used as seedling substrates and were mixed well. We further divided the nursery pond into suitable areas by using polyvinylchloride (PVC) board dividers $(10.0 \mathrm{~cm}$ high),

Received for publication 2 Dec. 2020.

Published online 22 March 2021.

We are thankful for the planting site provided by Senhai Landscape Construction Co., Ltd. (lat. 34. $0784^{\circ} \mathrm{N}$, long. $109.1021^{\circ} \mathrm{E}$ ), Nanjing Langchi Agricultural Science and Technology Development Co. Ltd. (lat. $31.9406^{\circ} \mathrm{N}$, long. $118.9279^{\circ} \mathrm{E}$ ), and Xi'an Hengfeng Biotechnology Co., Ltd. (lat. 34. $1099^{\circ} \mathrm{N}$, long. $108.5977^{\circ} \mathrm{E}$ ) during our experiment. This study was financially supported by the Key R\&D Program of Shaanxi Province (2019SF-307 and 2018FP2-26), the Fundamental Research Funds for the Central Universities (GK201906008 and GK201806006), the National Natural Science Foundation of China (31670299), Graduate Education and Teaching Reform Research project (GERP-20-41) and the National Key Technologies R \& D Program for Modernization of Traditional Chinese Medicine (2017YFC1701300 and 2017YFC1700706).

All experiments were performed within the limits of national policy of China.

The data used to support the findings of this study are available from the corresponding author upon request.

J.F.N. and Z.Z.W. conceived and designed the experiments. Z.Y.M. and D.H.L. performed the experiments. S.Q.W. and G.H.J. analyzed the data. Z.Y.M. drafted the manuscript, J.F.N. and Z.Z.W. revised it. All authors have discussed and commented on the manuscript.

J.F.N. and Z.Z.W. are the corresponding authors. E-mail: niujunfeng@snnu.edu.cn or zzwang@snnu. edu.cn.

This is an open access article distributed under the CC BY-NC-ND license (https://creativecommons. org/licenses/by-nc-nd/4.0/).

Table 2. Different hormone combinations for $B$. striata seedling growth.

\begin{tabular}{lccc}
\hline & \multicolumn{2}{c}{ Combination of hormone levels } & \\
\cline { 2 - 3 } Medium & Banana juice $(\mathrm{g} / \mathrm{L})$ & $\mathrm{NAA}(\mathrm{mg} / \mathrm{L})$ & Vaccinations \\
\hline 1 & 50 & 0.3 & 9 \\
2 & 50 & 0.5 & 9 \\
3 & 50 & 0.7 & 9 \\
4 & 70 & 0.3 & 9 \\
5 & 70 & 0.5 & 9 \\
6 & 70 & 0.7 & 9 \\
\hline
\end{tabular}

NAA = naphthylacetic acid.

Table 3. Transplanting matrix formulation.

\begin{tabular}{ll}
\hline Experimental group & \multicolumn{1}{c}{ Volume ratio of the substrate } \\
\hline Group 1 & Humus: sand: bark (scrap) $=3: 1: 1$ \\
Group 2 & Humus: sand: bark (powder) $=5: 3: 2$ \\
Group 3 & Humus: sand: pine needles $=4: 1: 2$ \\
Group 4 & Nutrient soil: perlite: bark (powder) $=5: 2: 1$ \\
Group 5 & Native soil \\
\hline
\end{tabular}

Table 4. Different seeding substrate ratios.

\begin{tabular}{llc}
\hline Serial number & \multicolumn{1}{c}{ Substrates } & Ratio of the seeding substrate \\
\hline A & Bark powder: humus: nutrient & $15: 20: 8: 1: 5$ \\
& soil: chicken powder: peat soil & \\
B & Peat soil: Huangjiang residue: river sand & $3: 1: 1$ \\
C & Peat soil: river sand & $3: 1$ \\
D & Huangjiang residue & - \\
\hline
\end{tabular}

Huangjiang residue is the plant residue of Dioscorea zingiberensis.

sprayed insecticide, and covered the nursery pond with nonwoven fabric.

To reduce production costs, we preferentially selected local seedling-raising substrates in Shaanxi Province to conduct the experiments (Table 4). During production, different substrates were mixed and placed in a nursery pond with a thickness of $8.0 \mathrm{~cm}$.

After peeling the preserved seeds with normal vigor, they were mixed with NAA and talcum powder at a weight ratio of 1:5:5.0 $\times 10^{4}$ and sifted through a sieve (40 holes per $\mathrm{cm}^{2}$ ) for sowing at a seeding density of $3.0 \times 10^{-3} \mathrm{~kg} / \mathrm{m}^{2}$. After seeding, the seeds were sprayed with a nozzle and the plastic greenhouse was closed. The air temperature was maintained at 20 to $35^{\circ} \mathrm{C}$ with humidity of more than $60 \%$. Water was sprayed regularly to ensure that the substrate surface was moist.

According to the germination process of orchids, seeds can be divided into five stages: 1) the seed absorbs water, the embryo expands and breaks through the testa, and the rhizoid also appears; 2) the embryo continues to grow and the test rhizoid continues to increase; 3) protocorm and leaf primordium form; 4) true leaves elongate and the protocorm continue to swell; 5) the root appears (Fig. 1). When the seeds germinated to the fifth stage, the ventilation time of the greenhouse was gradually increased and the humidity was slowly reduced.

When the first leave sprouted, a $0.5 \%$ water solution of phosphoric acid diamine was sprayed on the seedlings every week. When the seedlings sprouted two to three leaves, the humidity in the greenhouse was reduced to $50 \%$ and the greenhouse was ventilated every night.

Data processing.

Germination rate $=$ seed germination/

sowing number $\times 100 \%$

Transplanting survival rate

$=$ number of viable seedlings after transplanting/number of transplanted seedlings $\times 100 \%$.

Leaf proliferation ratio

$=$ number of new leaves

/number of leaves before inoculation.

All data in this study were evaluated using SPSS 17.0 software to analyze variances in the test data. The least significant difference method was used for multiple comparisons between experimental groups, and DPS software (Middlesex, UK) was used to create charts.

\section{Results}

Screening results of the germination medium. The results of TTC staining revealed that the seed viability of fresh, matured $B$. striata seeds was $93.4 \%$, whereas the vigor of the seeds stored in the laboratory for more than 6 months was $83.4 \%$.

After $15 \mathrm{~d}$ of inoculation, the seeds in experimental groups 3, 5, and 7 began to germinate successively, whereas the seeds in the other experimental groups germinated 
$30 \mathrm{~d}$ later. The germination rates of the seeds in each experimental group were recorded and statistically analyzed. It can be seen from the experimental results (Table 5) that the type of growth media had a significant influence on the germination of the $B$. striata seeds.

According to the results in Table 6, the medium type was the main factor affecting seed germination, followed by the contents of NAA and 6-BA. Through the orthogonal experiment results, we obtained the best combination of various factors $\left(A_{1} B_{3} C_{3}\right)$, among which $\mathrm{MS}+6-\mathrm{BA} 2.0 \mathrm{mg} / \mathrm{L}+\mathrm{NAA}$ $1.0 \mathrm{mg} / \mathrm{L}$ exhibited the best effects on inducing seed germination. The average germination rate of $B$. striata seeds with the optimal combination of hormones was $91.8 \%$.

Screening results of the rooting medium. After $30 \mathrm{~d}$ of culturing, we observed from the statistical results (Table 7) that the average root numbers of the seedlings in experimental groups 3, 4, and 5 were significantly higher than those of the other groups. Furthermore, the proliferation multiples of leaves in experimental groups 1,4 , and 5 were $3.1,2.4$, and 2.2 , which indicated that banana juice promoted the advanced root induction of seedlings, whereas the appropriate concentration of NAA promoted the proliferation of $B$. striata leaves. Concurrently, the leaves of the plants were green and grew well in group 5. Therefore, MS + banana juice $(70 \mathrm{~g} / \mathrm{L})+$ NAA $(0.5 / \mathrm{L})$ were selected as the rooting medium.

Screening results of the transplanting substrate. It could be observed from multiple comparisons that the survival rates of the different transplanting substrates and tube seedlings had significant effects. On day 15 after transplantation, the survival rate of the test tube seedlings in group 1 was the highest $(93.183 \pm 1.877)$ (Table 8). On day 30 after transplantation, the survival rate with the group 1 substrate was the highest $(82 \%)$ and was significantly superior to that of the other substrates.

The group 5 substrates were in situ soil. Although the substrate nutrients were insufficient, the survival rate after transplantation was still $70.4 \%$. The survival rate of the transplanted matrix in group 2 was $30.5 \%$. The survival rate of the group 3 substrate was the lowest $(7.6 \%)$.

Screening results of the direct seeding substrate. By conducting direct seeding experiments with $B$. striata on different substrates, the seeds germinated to stage 1 or 2 on day 5 . After $24 \mathrm{~d}$, stage 3 was attained; the seeds turned green and leaf primordia formed. On day 45 , the seeds germinated to stage 4 or 5, the leaf primordium continued to grow, the first true leaf began to grow, and fibrous roots appeared (Fig. 2). During this experiment, only the process of the emergence of real leaves and fibrous roots was considered normal germination; otherwise, it was regarded as abnormal germination. According to the germination of $B$. striata seeds, the germination rate of substrate $B$ was significantly higher than that of the other
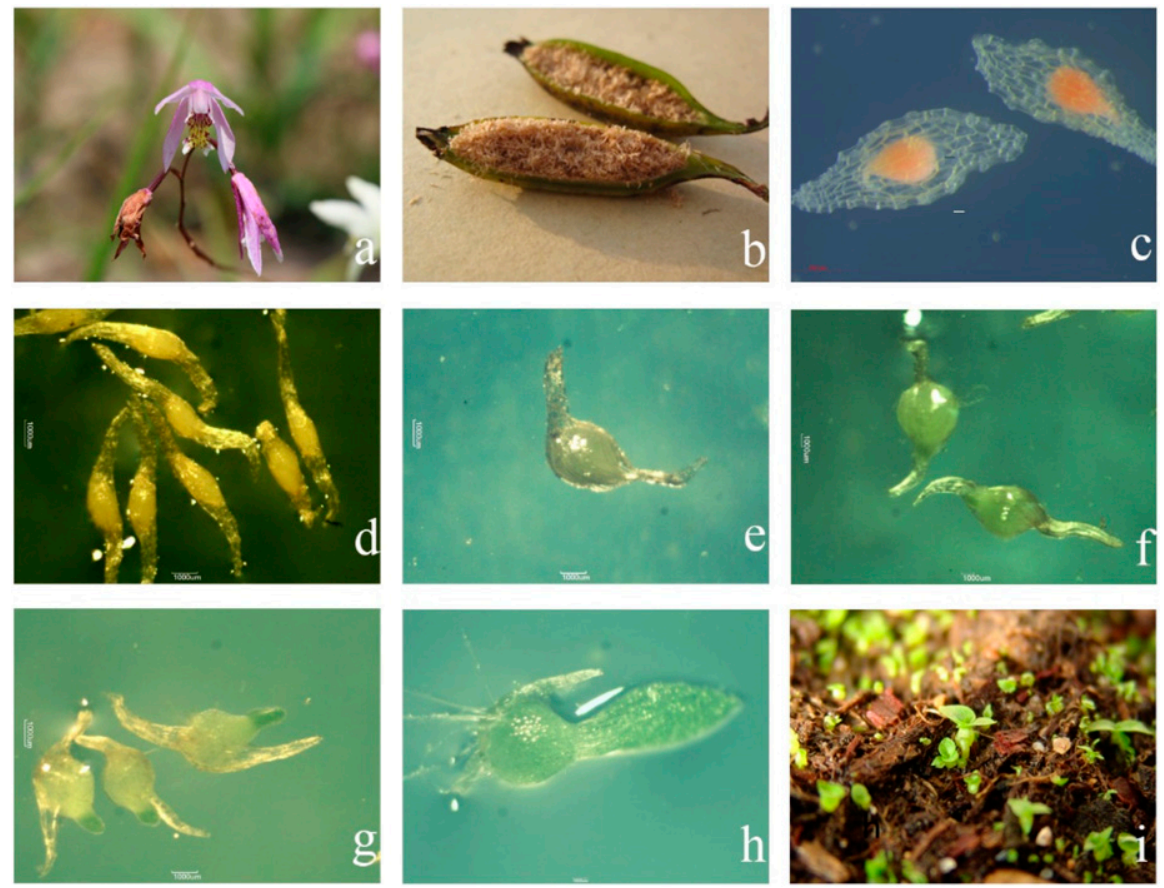

Fig. 1. Progress of B. striata seed germination. (A) Flower shape of B. striata. (B) Fruit anatomy diagram. (C) TTC staining of $B$. striata seeds. (D-H) Five signature stages of $B$. striata seed germination. (I) Seed germination in the matrix.

Table 5. Orthogonal test results.

\begin{tabular}{lcccc}
\hline Experimental group & $\begin{array}{c}\text { Medium } \\
\text { (type A) }\end{array}$ & $\begin{array}{c}6-\mathrm{BA} \mathrm{B} \\
(\mathrm{mg} / \mathrm{L})\end{array}$ & $\begin{array}{c}\text { NAA C } \\
(\mathrm{mg} / \mathrm{L})\end{array}$ & $\begin{array}{c}\text { Germination } \\
\text { rate }(\%)\end{array}$ \\
\hline 1 & $\mathrm{MS}$ & 0.0 & 0.0 & 52.00 \\
2 & $\mathrm{MS}$ & 1.0 & 0.5 & 71.00 \\
3 & $\mathrm{MS}$ & 2.0 & 1.0 & 87.00 \\
4 & $1 / 2 \mathrm{MS}$ & 0.0 & 0.5 & 65.00 \\
5 & $1 / 2 \mathrm{MS}$ & 1.0 & 1.0 & 75.00 \\
6 & $1 / 2 \mathrm{MS}$ & 2.0 & 0.0 & 68.00 \\
7 & Water agar & 0.0 & 1.0 & 22.00 \\
8 & Water agar & 1.0 & 0.0 & 33.00 \\
9 & Water agar & 2.0 & 0.5 & 32.00 \\
K1 & 210.00 & 138.99 & 147.00 & 168.00 \\
K2 & 204.00 & 179.01 & 183.99 & 49.00 \\
K3 & 87.00 & 183.00 & 56.00 & \\
k1 & 70.00 & 46.33 & 61.33 & \\
k2 & 68.00 & 59.67 & 12.33 & \\
k3 & 29.00 & 61.00 &
\end{tabular}

6-BA = 6-benzylaminopurine; $\mathrm{MS}=$ Murashige and Skoog; NAA = naphthylacetic acid. 1/2MS refers to half of the macroelements in MS. A = medium type; $\mathrm{B}=$ the concentration of $6-\mathrm{BA} ; \mathrm{C}=$ the concentration of NAA.

Table 6. Orthogonal test variance analysis.

\begin{tabular}{lcccccr}
\hline $\begin{array}{l}\text { Sources of } \\
\text { variation }\end{array}$ & $\begin{array}{c}\text { Sum of } \\
\text { squares }\end{array}$ & $\begin{array}{c}\text { Degrees of } \\
\text { freedom }\end{array}$ & $\begin{array}{c}\text { Mean } \\
\text { square }\end{array}$ & $\begin{array}{c}F \\
\text { value }\end{array}$ & $\begin{array}{c}P \\
\text { value }\end{array}$ & Significance \\
\hline Medium type & 3206.000 & 2 & 1603.000 & 19.709 & 0.048 & $*$ \\
6-BA & 394.667 & 2 & 197.333 & 2.426 & 0.292 & \\
NAA & 204.667 & 2 & 102.333 & 1.258 & 0.443 \\
Error & 162.667 & 2 & 81.333 & & & \\
Sum & 3968.000 & 8 & & & & \\
\hline
\end{tabular}

6-BA = 6-benzylaminopurine; NAA = naphthylacetic acid.

three groups. Therefore, as shown in Table 9, we selected substrate peat soil, Huangjiang residue, and river sand as the optimal seeding substrate in production.
Optimum results of the best substrate. To better reflect the direct seeding technology, the plant growth diagram of 120-d direct seeding was selected for this study. When 
Table 7. Different hormone combinations for B. striata seedling growth.

\begin{tabular}{lccl}
\hline $\begin{array}{l}\text { Medium } \\
\text { type }\end{array}$ & $\begin{array}{c}\text { Leaf } \\
\text { proliferation }\end{array}$ & $\begin{array}{c}\text { New rooting } \\
\text { number }\end{array}$ & \multicolumn{1}{c}{ Seedling development } \\
\hline 1 & 3.2 & $2.23 \pm 0.15 \mathrm{aA}$ & Green leaves, thin roots, faster growth \\
2 & 2.1 & $2.67 \pm 0.41 \mathrm{aA}$ & Green leaves, thicker roots, slower growth \\
3 & 1.6 & $2.10 \pm 0.11 \mathrm{aA}$ & Green leaves, roots slender, developed \\
4 & 2.4 & $2.98 \pm 0.27 \mathrm{aA}$ & Pale green leaves, roots robust, developed \\
5 & 2.2 & $3.67 \pm 0.24 \mathrm{aA}$ & Green leaves, thicker roots, faster growth \\
6 & 1.9 & $2.33 \pm 0.23 \mathrm{aA}$ & $\begin{array}{c}\text { Dark green leaves, thick and short roots, } \\
\text { misshapen, extremely slow growth }\end{array}$ \\
\hline
\end{tabular}

The letters represent the significance analysis results.

Table 8. Multiple comparisons of survival under different substrates treated after 15 and $30 \mathrm{~d}$.

\begin{tabular}{lcc}
\hline $\begin{array}{l}\text { Matrix } \\
\text { treatment }\end{array}$ & $\begin{array}{c}\text { Transplant } 15-\mathrm{d} \\
\text { survival rate }\end{array}$ & $\begin{array}{c}\text { Transplant 30-d } \\
\text { survival rate }\end{array}$ \\
\hline 1 & $93.183 \pm 1.877 \mathrm{Aa}$ & $82.000 \pm 1.455 \mathrm{aA}$ \\
2 & $71.533 \pm 2.182 \mathrm{bC}$ & $20.167 \pm 1.093 \mathrm{cdC}$ \\
3 & $65.750 \pm 1.621 \mathrm{cD}$ & $7.600 \pm 1.284 \mathrm{dD}$ \\
4 & $73.267 \pm 2.435 \mathrm{bC}$ & $30.517 \pm 2.281 \mathrm{cC}$ \\
5 & $90.567 \pm 1.659 \mathrm{aB}$ & $70.450 \pm 1.461 \mathrm{bB}$ \\
\hline
\end{tabular}

The letters represent the significance analysis results.
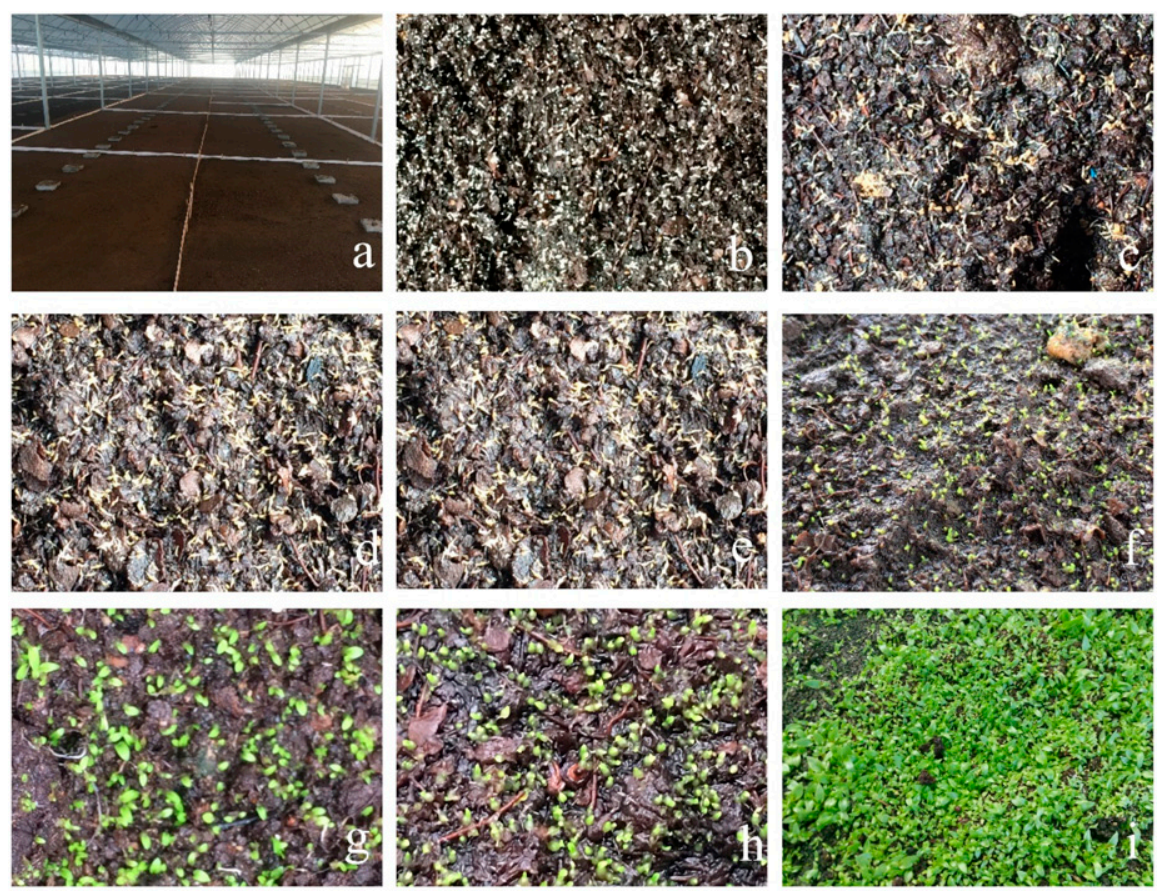

Fig. 2. Direct-seeding germination of B. striata seeds. (A) Unseeded. (B) The first day of sowing. The seeds were fusiform at stage 0 and did not germinate, but the embryo had activity. (C) At $5 \mathrm{~d}$ after sowing, the imbibition of seeds occurred. (D) At $8 \mathrm{~d}$ after sowing, the seeds absorbed water further and the volume of the embryo further increased. (E) At $15 \mathrm{~d}$ after sowing, the seeds reached the second stage, the embryo had broken through the seedcoat, and a large number of root-like bodies appeared. (F) At $24 \mathrm{~d}$ after sowing, the seeds were germinated to the third stage, the primary meristem appeared, and the primary base of the middle lobe was gradually formed. (G) At $35 \mathrm{~d}$ after sowing, the protocorm was further developed and the leaf primordium was gradually enlarged. (H) At $45 \mathrm{~d}$ after sowing, the first true leaf appeared and elongated in the fifth stage of germination. (I) The seeds entered the seedling growth stage at $120 \mathrm{~d}$ after sowing.

Table 9. Germination rates of different substrates.

\begin{tabular}{lrr}
\hline $\begin{array}{l}\text { Serial } \\
\text { number }\end{array}$ & \multicolumn{1}{c}{ Different substrates } & Germination rate \\
\hline $\mathrm{A}$ & $\begin{array}{c}\text { Bark powder: humus: nutrient soil: chicken } \\
\text { powder: peat soil }\end{array}$ & $0.6972 \pm 0.0313 \mathrm{~B}$ \\
$\mathrm{~B}$ & $\begin{array}{l}\text { Peat soil: Huangjiang residue: river sand } \\
\mathrm{C}\end{array}$ & $0.7415 \pm 0.0238 \mathrm{~A}$ \\
$\mathrm{D}$ & Peat soil: river sand & $0.6465 \pm 0.0228 \mathrm{C}$ \\
The letters in the germination rate column represent the significance analysis results between different groups.
\end{tabular}

the optimal matrix group B was broadcast, the seedlings emerged in a relatively orderly manner and the individual plants were relatively large. All of them grew two or three true leaves with heights of $6.0 \mathrm{~cm}$.

After $180 \mathrm{~d}$ of direct seeding, all the plants had four or five true leaves. Individual plant sizes ranged from 10.0 to $15.0 \mathrm{~cm}$, with welldeveloped roots and pseudobulbs of $\approx 1.0$ to $1.5 \mathrm{~cm}$. After reaching this stage, these seedlings can be transplanted to the field as finished seedlings.

\section{Discussion}

The basic ingredients of the growth media can provide plants with the nutrients they require for survival. However, the plants grow robustly only when these nutrients work in conjunction with the appropriate plant hormones (Franceschi et al., 2019). Therefore, the selection of hormones and the combination of appropriate concentrations were key factors for successful plant tissue culturing and an important breakthrough for the rapid proliferation of plants (Nie et al., 2016). The appropriate combination and concentrations of plant growth regulators such as NAA and 6-BA have a great influence on the growth and quality of plants (Matkowski, 2008; Wang et al., 2017).

It was found that abscisic acid is a positive regulator of dormancy induction and maintenance (Kucera et al., 2005), whereas NAA could effectively help to establish highfrequency protocorm-like bodies on the in vitro germinated seedlings of $S$. plicata Blume (Haque and Ghosh, 2017). Optimizing the culture medium using the orthogonal test method is a common experimental method. Zhang selected $1 / 2 \mathrm{MS}$ medium as the basic medium with $1 \% \mathrm{NaClO}, 2 \%$ sucrose, and $0.1 \%$ activated carbon; with this, the seed germination rate of $B$. striata was $80 \%$ (Zhang et al., 2019). During our experiment, we found that the optimal media ratio for seed germination was MS + 6-BA $(2.0 \mathrm{mg} / \mathrm{L})+$ NAA $(1.0 \mathrm{mg} / \mathrm{L})$; with this, the germination rate was effectively improved up to $91.8 \%$.

The growth and development of plants have their own inherent genetic patterns and sequences. In certain ambient environments, external materials and energy are used for the proliferation and differentiation of plants (Shao et al., 2017). During the process of development, the aboveground and underground plant components have a direct mutual promotion relationship; therefore, the evaluation of healthy plant growth largely depends on the development of its root system. Banana juice was found to promote root formation and growth for $D$. canducum (Couselo et al., 2012). During our experiment, we found that it was also beneficial for $B$. striata, whereas NAA was related to the proliferation of leaves (He et al., 2017b).

The direct seeding technology of $B$. striata has been reported for the first time in this article. During the screening test of transplanting substrates, the seedling survival rate was higher in the group with 

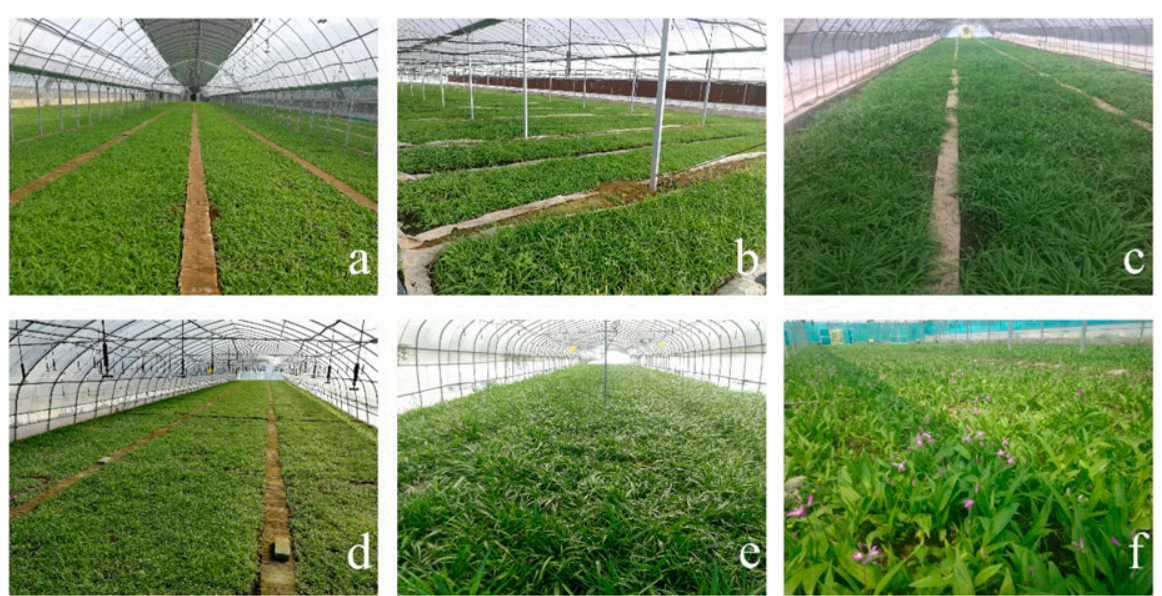

Fig. 3. Large-area planting for $B$. striata. (A) Yinzhen street base, Chang'an district, Xi'an, on day 200 of $B$. striata direct seeding. (B) Chunhua street base, Jiangning district, Nanjing, on day 205 of $B$. striata direct seeding. (C) Daizhao street base, Chang'an district, Xi'an, on day 220 of $B$. striata direct seeding. (D-F) Ganting street base, Huyi district, Xi'an, on days 215, 250, and 450 of $B$. striata direct seeding.

fermentative bark and a medium sediment concentration. This may be because river sand promoted drainage and increased the permeability of the soil to facilitate root respiration. Simultaneously, as the external protective structure of plants, bark is primarily used for the transport of nutrients and preventing diseases and pests (Geoffroy et al., 2017). The abundant nutrients in the bark were degraded to inorganic nutrients that are more easily absorbed by plants through fermentation. Several microorganisms grew during the fermentation process, which created a rich symbiotic environment for the transplantation of seedlings (Das et al., 2016). The natural habitats of some epiphytic orchids, such as many species of Dendrobium, can lead to epiphytes on tree trunks (Chen et al., 2015). Through analyses and comparisons, humus, river sand, and bark were found to be the best substrates for planting. The establishment of the direct seeding system was related to the fact that we treated the seeds with hormones during the early stage and then selected a matrix based on bark and Huangjiang residue during the later stage. It is possible that these elements provided the nutrients required for seed germination. However, the specific germination kinetics need to be further studied.

\section{Conclusions}

With the discovery of the high medicinal value of $B$. striata, and because of its clinical and industrial applications, its demand is increasing significantly. The direct seeding system we have developed greatly reduces the various conditions required for seed germination under natural conditions and provides a new artificial planting technique for the protection of excellent germplasm resources. This technology system adopts the method of sexual reproduction, which not only makes the offspring more viable and more adaptable to the environment but also significantly reduces the planting costs (from
$300,000 \mathrm{RMB} / \mathrm{ha}$ in 2015 to $9000 \mathrm{RMB} / \mathrm{ha}$ in 2019) and can increase production to 24,000 $\mathrm{kg} / \mathrm{ha}$. Furthermore, it can meet the needs of large-scale commercial production (Fig. 3) and also effectively protect the resources of this important, rare, and endangered species.

\section{Literature Cited}

Bai, J.Q., S. Gao, P.F. Wang, L. Wang, W.W. Liu, X.P. Wang, X.B. Zhang, and T.T. Shi. 2018. Bletilla striata planting area in Ningshan county extraction based on multi-temporal remote sensing images. CJCMM 44:4129-4133, doi: 10.19540/j.cnki.cjemm.20190731.112.

Briggs, D. E., S. M. Sole, and P. Latham. 2009. Tetrazolium staining, mitochondria, and barley quality. J. Inst. Brew 115:41-48, doi: 10.1002/ j.2050-0416.2009.tb00343.x.

Chen, H., L. Zheng, C.Y. Mei, Z.P. Gong, Y.J. Li, S.Y. Chen, Y.Y. Lan, Y.L. Wang, A.M. Wang, Y.T. Li, and Y. Huang. 2019. Simultaneous determination of three bioactive constituents from Bletilla striata by UPLC-MS/MS and application of the technique to pharmacokinetic analyses. Evid.-based Complement Altern. Med. 2019:1-10, doi: 10.1155/2019/ 8942512.

Chen, N., H.J. Chen, M. Sang, S. Ding, and H. Yu. 2015. Discrimination and similarity evaluation of tissue-cultured and wild dendrobium species using Fourier transform infrared spectroscopy. J. Mol. Struct. 1086:255-265, doi: 10.1016/ j.molstruc.2015.01.027.

Chen, N.D., T. You, J. Li, L.T. Bai, J.W. Hao, and X.Y. Xu. 2016. A comparative study of three tissue-cultured Dendrobium species and their wild correspondences by headspace gas chromatography-mass spectrometry combined with chemometric methods. J. Food Drug Anal. 24:839-847, doi: 10.1016/j.jfda.2016.05.006.

Couselo, J.L., E. Corredoira, A.M. Vieitez, and A. Ballester. 2012. Plant tissue culture of fastgrowing trees for phytoremediation research. Methods Mol. Biol. 877:247-263, doi: 10.1007/ 978-1-61779-818-4_19.

Das, A.A.K., J. Bovill, M. Ayesh, S.D. Stoyanov, and V.N. Paunov. 2016. Fabrication of living soft matter by symbiotic growth of unicellular microorganisms. J. Mater. Chem. B Mater. Biol. Med. 4(21):3685-3694, doi: 10.1039/ C5TB02489G.
Franceschi, C.R.B., E.C. Smidt, L.N. Vieira, and L.L.F. Ribas. 2019. Storage and in vitro germination of orchids (Orchidaceae) seeds from Atlantic Forest Brazil. An. Acad. Bras. Cienc. 91:E20180439, doi: 10.1590/0001-3765201920180439.

Geoffroy, T.R., Y. Fortin, and T. Stevanovic. 2017. Hot-water extraction optimization of sugar maple (Acer saccharum Marsh.) and red maple (Acer rubrum L.) bark applying principal component analysis. J. Wood Chem. Technol. 37(4-6):261-272, doi: 10.1080/ 02773813.2017 .1279631 .

Guler, N. 2016. Seed micromorphology of Orchis Tourn. ex L. (Orchidaceae) and allied genera growing in Edirne province, Turkey. PhytoKeys 68:9-25, doi: 10.3897/phytokeys.68. 8746.

Haque, S.M. and B. Ghosh. 2017. Regeneration of cytologically stable plants through dedifferentiation, redifferentiation, and artificial seeds in Spathoglottis plicata Blume. (Orchidaceae). Hort. Plant J. 3:199-208, doi: 10.1016/j.hpj.2017. 10.002 .

He, H., J. Qin, X. Cheng, K. Xu, L. Teng, and D. Zhang. 2017a. Effects of exogenous 6-BA and NAA on growth and contents of medicinal ingredient of Phellodendron chinense seedlings. Saudi J. Biol. Sci. 25:1189-1195, doi: 10.1016/j.sjbs.2017.11.037.

He, X., X. Wang, J. Fang, Z. Zhao, L. Huang, H. Guo, and X. Zheng. 2017b. Bletilla striata: Medicinal uses, phytochemistry and pharmacological activities. J. Ethnopharmacol. 195:20-38, doi: 10.1016/j.jep.2016.11.026.

Hirano, T., T. Godo, M. Mii, and K. Ishikawa. 2005. Cryopreservation of immature seeds of Bletilla striata by vitrification. Plant Cell Rep. 23(8):534, doi: 10.1007/s00299-0040893-9.

Huang, Y. and F. Lee. 2010. An automatic machine vision-guided grasping system for phalaenopsis tissue culture plantlets. Comput. Electron. Agr. 70:42-51, doi: 10.1016/j.compag.2009.08.011.

Jiang, S., C.F. Chen, X.P. Ma, M.Y. Wang, W. Wang, Y. Xia, N. Zhang, M.K. Wu, and W.D. Pan. 2019. Antibacterial stilbenes from the tubers of Bletilla striata. Fitoterapia 138:104350, doi: 10.1016/j.fitote.2019.104350.

Kucera, B., M.A. Cohn, and G. Leubner-Metzger. 2005. Plant hormone interactions during seed dormancy release and germination. Seed Sci. Res. 15:281-307, doi: 10.1079/SSR2005218.

Li, M.Y., B. Ding, W.P. Huang, J.L. Pan, Z.S. Ding, and F.S. Jiang. 2018. Induction and characterization of tetraploids from seeds of Bletilla striata (Thunb.) Reichb.f. BioMed Res. Intl. 2018:1-8, doi: 10.1155/2018/3246398.

Matkowski, A. 2008. Plant in vitro culture for the production of antioxidants-a review. Biotechnol. Adv. 26:548-560, doi: 10.1016/j.biotechadv. 2008.07.001

Nie, N., Y. Zhu, M. Tian, J.W. Hua, L. Wang, and M.J. Qin. 2016. Morphological and cytohistological observations of seed germination and protocorm development of Bletilla striata. CJCMM 41:1446-1449, doi: 10.4268/cjcmm20160813.

Sarker, S.K., N. Begum, D. Mondal, M.A. Siddique, and M.A. Rashid. 2010. In vitro study of antiamoebic effect of methanol extract of mature seeds of Carica papaya on trophozoites of entamoeba histolytica. Bangladesh J. Pharmacol. 5:45-47, doi: 10.3329/bjp.v5i1. 5003.

Shao, S.C., K.S. Burgess, J.M. Cruse-Sanders, Q. Liu, X.L. Fan, H. Huang, and J.Y. Gao. 2017. Using in situ symbiotic seed germination to restore over-collected medicinal orchids in 
southwest China. Front. Plant Sci. 8:888, doi: 10.3389/fpls.2017.00888.

Sobolev, V.S., V.A. Orner, and R.S. Arias. 2013. Distribution of bacterial endophytes in peanut seeds obtained from axenic and control plant material under field conditions. Plant Soil 371: 367-376, doi: 10.1007/s11104-013-1692-2.

Wang, J., J.I. Li, J. Li, J.X. Li, S.J. Liu, L.Q. Huang, and W.Y. Gao. 2017. Production of active compounds in medicinal plants: From plant tissue culture to biosynthesis. Chin Herb. Med. 9:115-125, doi: 10.1016/S16746384(17)60085-6.

Wei, X.M., Y. Liu, X.Y. Wang, Z.T. Gao, S.M. Yao, and J.P. Han. 2018. Progress on research of tissue culture of Bletilla striata. Chin. Herb. Med. 10:23-26, doi: 10.1016/ j.chmed.2017.12.002.
Xu, D., Y. Pan, and J. Chen. 2019. Chemical constituents, pharmacologic properties, and clinical applications of Bletilla striata. Front. Pharmacol. 10:1168, doi: 10.3389/fphar.2019.01168.

Zhang, M., Q. Shao, E. Xu, Z. Wang, Z. Wang, and L. Yin. 2019. Bletilla striata: A review of seedling propagation and cultivation modes. Physiol. Mol. Biol. Plants 25:601-609, doi: 10.1007/s12298-019-00644-w. 